Research Article

\title{
Understanding the Effects of Fare Discount Schemes to Metro Transit Ridership Based on Structural Change Analysis
}

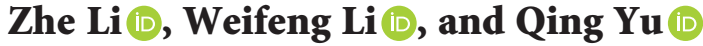 \\ Key Laboratory of Road and Traffic Engineering of the Ministry of Education, Tongji University, Tongji 201804, China \\ Correspondence should be addressed to Weifeng Li; liweifeng@tongji.edu.cn
}

Received 5 July 2021; Accepted 18 September 2021; Published 7 October 2021

Academic Editor: Thomas Hanne

Copyright $\odot 2021$ Zhe Li et al. This is an open access article distributed under the Creative Commons Attribution License, which permits unrestricted use, distribution, and reproduction in any medium, provided the original work is properly cited.

\begin{abstract}
Since fare discounts have been regarded as an effective economical measure to increase passenger flow, it is helpful for local governments and transit operators to understand its impact on ridership. Taking Xiamen, China, as an example, this study uses transaction data to analyze the changes of weekday daily metro ridership after the opening of Xiamen Metro Line 1 . At the initial stage of operation of Xiamen Metro Line 1, there are three preferential schemes: discount per trip, money reduced per trip, and discount after reaching the accumulated fare. Therefore, the algorithm of the iterated cumulative sums of squares is introduced to identify structural change points of the time series of daily ridership, which varies according to the type of ticket. The effects of different fare discounts on total ridership and ridership varied by ticket types are analyzed by the regression discontinuity method. The results show that the dates of structural change points are well-matched with the start and end dates of preferential schemes. Each preferential scheme has its own benefited groups. During the fare discount period, the number of passengers gradually increased. But after the cancellation of the favorable preferential scheme, the number of passengers decreased sharply. By understanding the impact of fare discounts on ridership in Xiamen, China, several metro ticketing policy recommendations are put forward, including raising the focus on E-Tickets, formulating more attractive preferential measures to promote the mode conversion of private cars and vehicles to metro, paying attention to high-frequency passengers, and seeking common subsidies from the financial industry to achieve a win-win situation. In addition, the analytical framework proposed in this study can be used to evaluate the effectiveness of other transportation policies in the future.
\end{abstract}

\section{Introduction}

In recent years, metro systems have developed rapidly in China. According to the data from the China Association of Metros, 19 cities have opened their first metro lines in the past 5 years. There have been 244 operating lines with a mileage of $7,970 \mathrm{~km}$ in China [1]. As a kind of large-capacity public transport, the metro system is considered the main skeleton of the public transport system. The opening of the first metro line may lead to a modal shift from the bus and private cars to the metro $[2,3]$. Therefore, the government and metro operators are very concerned about the changes in ridership after the opening of the first metro line.

Due to the social benefit of public transport, passengers are more sensitive to prices and expect lower costs. During the opening period of the first metro line, several fare discount schemes are launched to attract stable passenger flow. Generally speaking, as a type of economic measure, fare discount schemes can have a positive impact on metro passenger flow [4]. However, if local government and transit operators lack experience in these fields, inappropriate fare discount policies may lead to a sharp decline in transit ridership and cause negative public reactions due to social inequality. Yang held the view that it is difficult to balance revenue, profit, demand, user benefits, and social welfare when determining ticket prices [5]. Therefore, it is necessary to explore the impact of fare discount schemes on ridership.

With the development of data collection progress, the emerging spatiotemporal data can help explore travel behavior and improve urban transport $[6,7]$. In addition, it is 
possible to monitor dynamic ridership for a long time, which provides us with a database to explore the impact of fare discount schemes on ridership. At the same time, with the popularity of smartphones, ticket types have also been revolutionized. Passengers can get E-Tickets through their smartphones. They no longer need to buy tickets from Ticket Vending Machine or carry a smart card with them. E-Tickets are attractive to many young people who are familiar with smartphones. At the same time, it is difficult for older passengers who are not familiar with smartphones to use E-Tickets. In general, E-Tickets have become an important ticket type and pose a subversive challenge to traditional ticket types such as Smart Card Tickets and Single Tickets. Therefore, studying the impact of different fare discount schemes on ridership of different ticket types, especially emerging ticket types, will help the government and operators to evaluate the effect of fare discount schemes. Meanwhile, the study can lay a foundation for the introduction of targeted preferential policies of different ticket types.

Smart Card Tickets, E-Tickets, Single Tickets, and Other Tickets can be used in the Xiamen Metro system. Fare discount schemes are issued by the government, metro companies, and Banking Alliance in China (UnionPay). We observed the results of fare discount schemes implemented in Xiamen City over the past 18 months, including discount per trip, money reduced per trip, and discount after reaching the accumulated fare. This case provides a reference for studying the impact of discount types on ridership. To reveal the different trends of ridership caused by the fare discount schemes of different ticket types, the iterated cumulative sums of squares (ICSS) algorithm is adopted in this study [8].

The main purposes of this paper are to (1) propose an analysis method to extract the variation of ridership and (2) discuss the impact of fare discount schemes on ridership after the opening of the first metro line. The remainder of this paper is organized as follows. In Section 2, relevant research studies are reviewed. In Section 3, the background of Xiamen city, the metro system of Xiamen, and its transaction data are introduced. The ICSS and RD algorithm are presented in Section 4. Policy recommendations are put forward based on analyzing the association between the structural change of ridership and the fare discount schemes in Section 5. Finally, Section 6 summarizes the main findings of this study.

\section{Related Works}

2.1. Early Studies of Transit Fare. In the early literature, Vickrey formulated transit fares based on the traditional marginal cost pricing theory [9]. Subsequently, Mohring developed a microeconomic foundation for public transportation services with fixed demand [10]. After completing an important empirical study, Small introduced the concept of generalized costs and calibrated the disutility function [11]. Attitude theory, social learning theory, and theories of social dilemmas were also developed when researching fare policies [12].
Fare elasticity is the most widely used method to evaluate the impact of fares on ridership. Price sensitivity is measured by elasticities, which refers to the percentage change in consumption caused by a one-percent change in price, all else held constant. A frequently used rule-of-thumb, known as the Simpson-Curtin rule, is that each $3 \%$ fare increase reduces ridership by $1 \%$. Like most rules-of-thumb, this can be useful for rough analysis but it is too simplistic and outdated for detailed planning and modeling. Victoria Transport Policy Institute has reviewed the researches on fare elasticity. Some factors that affect transit elasticities are summarized as follows: user type, trip type, transit type, period, geography, type and direction of price change, etc. [13]. After a detailed review of international studies, Goodwin obtained the average elasticity values by different modes in the short run and long run. For instance, the elasticities of bus demand concerning fare cost are -0.28 in the short run and -0.55 in the long run. He noted that price impacts tended to increase over time because consumers have more options (related to increases in real incomes, car ownership, and telecommunications replacing physical travel) [14]. Gillen summarized transit fare elasticities for different user groups and trips types, illustrating how various factors affected transit price sensitivities. For example, it indicated that car owners had a greater elasticity $(-0.41)$ than people who relied on public transport $(-0.10)$, and work trips were less elastic than shopping trips [15]. Several fare discounts schemes have been launched to stimulate transit ridership. Public transportation ridership increased by $2-3 \%$ when public transportation subsidies increased by $10 \%$ and price decreased by $5-7 \%$ from a study by Cervero on urban public transportation in 18 countries [16].

Early methods are still quite useful for long-term public transit service planning in a static sense.

2.2. Measurement Models. In recent research, there have been four main measurement models proposed to determine the impact of transit fare discounts.

2.2.1. Optimization Models. The optimization model refers to the establishment of the objective function. When the objective function is optimal, the value of fare will be observed. The optimization model is mostly used to compare fare policies under different scenarios. Borndörfer et al. proposed a nonlinear optimization approach to pursue objectives such as the maximization of demand, revenue, profit, or social welfare [17]. Guo and Sun established two objective functions to analyze the fare discounts in terms of travel behavior, crowding, and waiting time [18].

2.2.2. Disaggregate Models. Disaggregate models mainly use survey data, combined with the user's social and economic attributes, to analyze the impact of fare change on individual passengers. Sharaby and Shiftan constructed a multinomial logit (MNL) model by using fare-box data and onboard survey data to analyze the impact of fare integration on travel behavior and transit ridership. The results indicated an increase of $7.7 \%$ in passenger trips and $18.6 \%$ in boarding. 
The number of boarding per trip increased from 1.38 to 1.52. The modal results demonstrated that fare reduction encouraged travelers to shift from private cars or taxis to buses, and created new trips [4]. Farber et al. assessed equity of transit fare based on distance using household travel survey data based on a joint ordinal/continuous model [19].

2.2.3. Regression Models. Regression models are regularly built with survey data from the macro-level to analyze the impact of fare changes on ridership and travel behavior. There are two main types of regression models, the first of which are temporal regression models. Miller and Savage analyzed the demand response after fare changes in 2004, 2006, 2009, and 2013 based on the pooled regression (POLS) and fixed effects models [20]. Gkritza et al. established seemingly unrelated regression equation (SURE) models for monthly data from January 1995 to December 2006 (a total of 144 observations) to estimate multimodal transit ridership with a varying fare structure [21]. Spatial regression models are the second type of regression model. Liu et al. evaluated the effects of public transport fare policy changes together with built and nonbuilt environment features on ridership by using a spatial lag regression model [22]. Verbich and El-Geneidy discovered the association between fare structure and social vulnerability using a negative binomial regression model with smart card data [23].

2.2.4. Statistical Models. It mainly refers to the fare elasticity analysis method. Nahmias-Biran et al. introduced the Lorenz curve and the Gini Index from the perspective of macroeconomics to summarize the equity aspects of transit fare change projects [24]. Using detailed travel-diary data, Brown investigated equity of low-income and higher-income transit riders under five evaluated fare structures: flat, adjusted by travel distance, varied by time of day, varied by mode, and discounted based on rider characteristics [25]. Nuworsoo et al. used onboard survey data to evaluate the impacts of the various fare proposals (hikes, base fare reductions, eliminations of free transfers, and discontinuation of periodic passes) on different subsets of riders and to evaluate the equity of each proposal. Proposals for flat fares per ride were found to be the least equitable of the fare policies, even when the base fare was lowered, because lower-income riders, youth, and minorities make more trips and transfer more frequently than their more affluent counterparts [26]. Wang et al. assessed the impact on ridership by using prior stated preference (SP) survey data (2015) and ex-post smart card data (2017), respectively. The results showed that the SP survey significantly exaggerated the passengers' responses to the price adjustment $[27,28]$.

Sensitivity analysis and price elasticities are common methods to analyze the impact of fare changes on ridership and travel behavior.

2.3. Summary of Relevant Research. Previous studies are long-term static research, using data sources from the traveldiary, onboard survey, SP survey, etc. With the development of data collection methods, it is possible to collect and summarize daily ridership from transaction data. After the opening of the first metro line, the government and metro operators look forward to receiving timely feedback from passengers on fare policy. Therefore, a short-term dynamic ridership monitoring method is more worthy of expectation. Yeh and Lee analyzed the structural change of monthly ridership time series from 2001 to 2014 [12]. It provides the possibility for researching on effects of fare policy on ridership according to structural change analysis.

\section{Study Case and Data}

3.1. Xiamen City and Xiamen Metro Line 1. Xiamen City is an important central coastal city on the southeastern coast of China, with a population of 4.01 million. As one of the more developed cities in China, Xiamen's foreign population from other cities accounts for about $42.38 \%$. Xiamen City is a famous tourist city in China. In 2018, there were 89 million tourists, with total tourism revenue of 140 billion RMB (RMB is the Chinese monetary unit, and $1 \mathrm{RMB}$ is equal to 0.1545 US dollars). The most popular tour dates in Xiamen are from June to October, especially during the summer vacation.

Xiamen Metro Line 1, the first metro in Xiamen, began operation on Dec $31^{\text {st }}, 2017$. It has 24 stations and is 30.3 kilometers long. By the end of 2018, the public transportation system in Xiamen was composed of 1metro line, 6 bus rapid transit (BRT) lines, and 358 bus lines (see Figure 1).

3.2. Metro Ticket Types and Fare Discount Schemes. There are four ticket types in the Xiamen metro:

(i) Smart Card Tickets: passengers swipe their smart cards when entering and exiting the station

(ii) E-Tickets (APP Tickets): passengers can purchase an electronic ticket through the "Xiamen Metro" mobile phone application, and they swipe their own E-Ticket/QR code via Bluetooth when entering and exiting the station

(iii) Single Tickets: passengers can only use this ticket once after selecting the entry and exit station on the Ticket Vending Machine. Single Tickets can be circulated and reused within the metro system

(iv) Other Tickets: multiday tickets, etc.

Xiamen Metro Line 1 adopts distance-based pricing. The further passengers travel, the lower fare per kilometer passengers pay. The ticket price will be calculated according to a segmentation system focusing on mileage: $2 \mathrm{RMB}$ within 4 kilometers, 3 RMB for $4-8$ kilometers, 4 RMB for $8-12$ kilometers, 5 RMB for 12-18 kilometers, 6 RMB for 18-28 kilometers, and 7 RMB above 28 kilometers.

The fare of Xiamen BRT also adopts distance-based pricing. The starting price of BRT is $1 \mathrm{RMB}$ within $10 \mathrm{ki}-$ lometers. For passengers traveling above 10 kilometers, they will pay $0.15 \mathrm{RMB}$ for traveling every one kilometer, and the maximum fare is $4 \mathrm{RMB}$. 


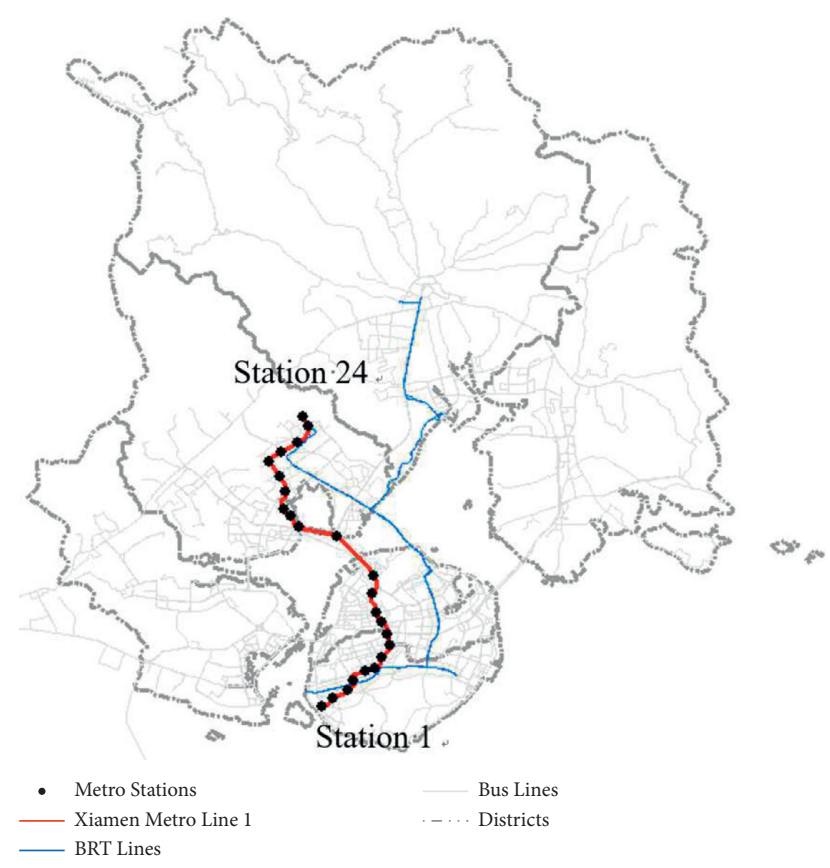

Figure 1: Xiamen city and Xiamen Metro Line 1.

The full fare of intra-district regular bus service is $1 \mathrm{RMB}$ per trip, and $2 \mathrm{RMB}$ for inter-district bus service.

Therefore, the original fare of the metro has no advantage over the fare of BRT and bus. To narrow the fare gap between different modes of transportation and enhance the attractiveness of Metro Line 1, the Xiamen government, Xiamen Metro Group, and Banking Alliance (UnionPay) have issued a series of preferential schemes. From Dec $31^{\text {st }}$, 2017 to Jun $30^{\text {th }}$, 2019, there were three fare discount schemes in Xiamen (see Table 1).

3.3. Metro Transaction Data. The metro transaction data used in this study were collected from Jan $1^{\text {st }}, 2018$ to Jun $30^{\text {th }}, 2019$ (a total of 18 months and 546 days) from the Xiamen Metro Group. Although there are separate records for each ticket type, there is a similar main field for each ticket type (see Table 2).

A total of 66.84 million metro transaction data records were collected in 18 months. Smart Card Tickets comprised the highest percentage of recorded tickets, accounting for $45.24 \%$ with 30.24 million records. The second-highest number of records was Single Tickets; there were 20.78 million records, accounting for $31.09 \%$. Only 11.60 million E-Tickets were recorded, accounting for $17.36 \%$. However, due to a series of preferential schemes, the share of E-Tickets increased from $12.93 \%$ ( $\operatorname{Jan} 1^{\text {st }}, 2018$ ) to $23.93 \%$ (Jun $30^{\text {th }}$, 2019) (see Table 3).

Statistically, there are significant differences in ridership on weekdays, weekends, and holidays (see Table 4). Xiamen is a very famous tourist city. Many citizens and tourists from other cities also take the subway to tourist attractions. Due to the short operation time, there is less commute travel on weekdays than leisure travel on weekends. Therefore, there is more ridership on weekends than ridership on weekdays.

\section{Methods}

\subsection{Iterated Cumulative Sums of Squares (ICSS) Algorithm}

4.1.1. Definition and Significance of Structural Change Points (SCPs). The iterated cumulative sums of squares (ICSS) algorithm were first introduced into the financial field to detect multiple changes of variance in a sequence of independent observations [8]. The calculation flow chart of the ICSS algorithm is shown in Figure 2. For additional details about the ICSS algorithm, please refer to the literature [8].

There are series that do not follow the usual assumption of constant variance underlying most models for time series. This series exhibits a stationary behavior for some time, then the variability of the error term changes suddenly; it remains constant again at this new value for some time until another change occurs.

ICSS algorithm is mainly used to detect the structural change points (SCPs) and test the mutation of the time series. The structural change points from ICSS are defined as the moment of state change. Rules can be obtained after analyzing the association between the date of ridership structural change points and the start-end dates of the fare discount schemes.

4.1.2. Constructing Fluctuation Rate Series and Stationary Test. The original daily transit ridership $\left\{R_{t}\right\}$ can be regarded as a time series. The fluctuation rate series $\left\{Q_{t}\right\}$ of daily transit ridership series $\left\{R_{t}\right\}$ is defined as the first-order logarithmic difference of daily transit ridership $\left\{R_{t}\right\}$ in

$$
Q_{t}=\ln R_{t+1}-\ln R_{t}, \quad t=0,1,2, \ldots, N,
$$

where $R_{t}$ is daily transit ridership at a certain line or station on date number $t$ and $N$ is the total number of dates. $\ln (x)$ is a synonym function of $x$.

Only when the time series is stable can its basic characteristics remain stable. These stable statistical characteristics can be used to obtain future forecasts. Before using the ICSS algorithm, it is necessary to check whether the fluctuation rate series $\left\{Q_{t}\right\}$ is a stationary time series.

If the time series meets the following criteria, it is a stationary time series:

(i) The average value $E\left(Q_{t}\right)=m$ is a constant $m$, independent of date number $t$.

(ii) The variance $\operatorname{Var}\left(Q_{t}\right)=s^{2}$ is a constant $s^{2}$, independent of date number $t$.

(iii) The covariance $\operatorname{Cov}\left(Q_{t}, Q_{t+k}\right)=g k$ is a constant $g k$. $k$ is the period interval of date number. $g$ is a constant coefficient. The covariance is independent of date number $t$.

The stationary of time series can be obtained by the logarithmic difference method, as shown in equation (2). The essence of the fluctuation rate series $\left\{Q_{t}\right\}$ is the growth rate of the original daily transit ridership $\left\{R_{t}\right\}$. Generally, the growth rate of the time series is stable. 
TABLE 1: Fare discount schemes.

\begin{tabular}{|c|c|c|c|c|}
\hline Discount name & Ticket type & Details & Allowance providers & $\begin{array}{l}\text { Start date- } \\
\text { end date }\end{array}$ \\
\hline $\begin{array}{l}10 \% \text { discount (discount per } \\
\text { trip) }\end{array}$ & $\begin{array}{c}\text { Smart } \\
\text { Card/APP }\end{array}$ & $\begin{array}{l}\text { Passengers can enjoy a } 10 \% \text { discount by using their } \\
\text { smart card/"Xiamen Metro" APP. }\end{array}$ & $\begin{array}{l}\text { Xiamen government } \\
\text { and Xiamen metro } \\
\text { group }\end{array}$ & $\begin{array}{l}2017 / 12 / 31 \\
\text { till now }\end{array}$ \\
\hline $\begin{array}{l}2 \mathrm{RMB} \text { discount (money } \\
\text { reduced per trip) }\end{array}$ & APP & $\begin{array}{l}\text { Passengers can enjoy a } 2 \text { RMB discount per trip by } \\
\text { using the "Xiamen Metro" APP and paying for the E- } \\
\text { tickets with the "UnionPay" APP. Each passenger can } \\
\text { only enjoy } 2 \text { preferential rides a day. }\end{array}$ & $\begin{array}{l}\text { Banking alliance } \\
\text { (UnionPay) }\end{array}$ & $\begin{array}{c}2018 / 9 / \\
22-2018 / \\
12 / 31\end{array}$ \\
\hline $\begin{array}{l}50 \% \text { discount (discount } \\
\text { after reaching accumulated } \\
\text { fare) }\end{array}$ & $\begin{array}{l}\text { Smart } \\
\text { Card/APP }\end{array}$ & $\begin{array}{l}\text { According to the monthly statistics, when the total } \\
\text { fare exceeds } 40 \mathrm{RMB} \text {, there is a more than } 50 \% \\
\text { discount for each ride. }\end{array}$ & $\begin{array}{l}\text { Xiamen government } \\
\text { and Xiamen metro } \\
\text { group }\end{array}$ & $\begin{array}{l}\text { 2018/12/1 till } \\
\text { now }\end{array}$ \\
\hline
\end{tabular}

TABLE 2: Main fields of metro transaction data.

\begin{tabular}{|c|c|c|c|}
\hline Name & $\begin{array}{l}\text { Data } \\
\text { type }\end{array}$ & Example & Note \\
\hline ID & String & $\begin{array}{l}\text { 04FBC094 (Single Tickets/Other Tickets); } \\
\text { 8012013030903604 (Smart Card Tickets); } \\
\text { 138xxxx4740 (E-tickets) }\end{array}$ & $\begin{array}{c}\text { The IDs of Single Tickets and Other Tickets are the } \\
\text { numbers on the card circled in the metro system and do } \\
\text { not belong to the passenger. While the IDs of smart cards } \\
\text { and E-Tickets are the passengers' individual information, } \\
\text { the IDs of smart cards are the smart card numbers, and the } \\
\text { IDs of E-Tickets are the encrypted registration telephone } \\
\text { numbers }\end{array}$ \\
\hline $\begin{array}{l}\text { Transaction } \\
\text { date }\end{array}$ & Date & $2019 / 1 / 1$ & \\
\hline $\begin{array}{l}\text { Transaction } \\
\text { time }\end{array}$ & Time & $6: 24: 09$ & \\
\hline $\begin{array}{l}\text { Transaction } \\
\text { type }\end{array}$ & Binary & $0 / 1$ & $\begin{array}{l}0 \text { stands for entering the metro station; } 1 \text { stand for exiting } \\
\text { the metro station }\end{array}$ \\
\hline Price & Int & 200 & Unit: RMB cent \\
\hline Gate number & String & 01010307 & $\begin{array}{l}\text { The metro station's name and number can be obtained } \\
\text { from the gate number }\end{array}$ \\
\hline
\end{tabular}

$Q_{t}=\ln R_{t+1}-\ln R_{t}=\frac{\ln R_{t+1}-\ln R_{t}}{(t+1)-(t)}=d\left(\ln R_{t}\right)=\frac{d\left(R_{t}\right)}{R_{t}}$,

where $d(x)$ is the derivation of $x$.

4.1.3. Constructing Uncorrelated Random Series. To avoid the effects of mean and variance, a series of uncorrelated random variables are constructed. Thus, the following uncorrelated random series $\left\{a_{t}\right\}$ are obtained after standardization ( $Z$-score normalization) in

$$
a_{t}=\frac{Q_{t}-1 / t \sum_{i=0}^{t-1} Q_{i}}{\sqrt{(t+1 / t) S_{Q}^{2}}}, \quad t=0,1,2, \ldots, N
$$

where $S_{Q}^{2}$ represents the estimated variance of all observations for fluctuation rate $Q_{t}$.

4.1.4. Constructing Centered Cumulative Sum of Squares. A series of the cumulative sum of squares are constructed to influence the effect of negative values of uncorrelated random variables. And, it also enhances and highlights the mutation in uncorrelated random series. Let $C_{t}$ be the cumulative sum of squares of a series of uncorrelated random variables $\left\{a_{t}\right\}$ in

$$
C_{t}=\sum_{i=0}^{t} a_{i}^{2}, \quad t=0,1,2, \ldots, N .
$$

Then, let $D_{t}$ be the centered (Zero-centered) cumulative sum of squares to avoid the effects of date number and detect whether the variances change significantly in

$$
D_{t}=\sqrt{\frac{N}{2}}\left|\frac{C_{t}}{C_{N}}-\frac{t}{N}\right|, \quad t=0,1,2, \ldots, N,
$$

where $C_{N}$ represents the value of $C_{t}$ when $t$ is equal to $N$.

4.1.5. Identification of SCPs. Obviously, $D_{t}$ against $t$ will oscillate around 0 for series with homogeneous variance. If the uncorrelated random series $\left\{a_{t}\right\}$ maintains the same value at each time, $D_{t}$ will be equal to 0 , which means that there are no SCPs in the fluctuation rate at time $t$.

Given a sudden change in the variance of $\left\{a_{t}\right\}$, when $D_{t}$ exceeds a predetermined threshold $D^{*}$ (here, it is set to $D_{0.05}^{*}=1.358$ at a confidence level of $95 \%$.), the existence of an SCP is implied. The time $t^{*}$ is regarded as the time when this SCP occurs. 
TABLE 3: Recorded numbers of metro transaction data for each ticket type.

\begin{tabular}{lcc}
\hline Ticket type & Record numbers for each ticket type & Percentage for each ticket type \\
\hline Smart Card Tickets & 30238762 & 45.24 \\
E-Tickets & 11600640 & 17.36 \\
Single Tickets & 20780222 & 31.09 \\
Other Tickets & 4220397 & 6.31 \\
Total & 66840021 & 100 \\
\hline
\end{tabular}

TABle 4: Statistical characteristics of ridership on weekdays, weekends, and holidays.

\begin{tabular}{lccc}
\hline Day type & Weekdays & Weekends & Holidays \\
\hline Numbers & 301 & 198 & 47 \\
Mean & 113918 & 130002 & 144902 \\
Median & 113936 & 130624.5 & 145001 \\
Standard deviation & 20636 & 20568 & 40792 \\
Maximum & 180077 & 176902 & 237830 \\
Minimum & 59218 & 85935 & 36295 \\
\hline
\end{tabular}

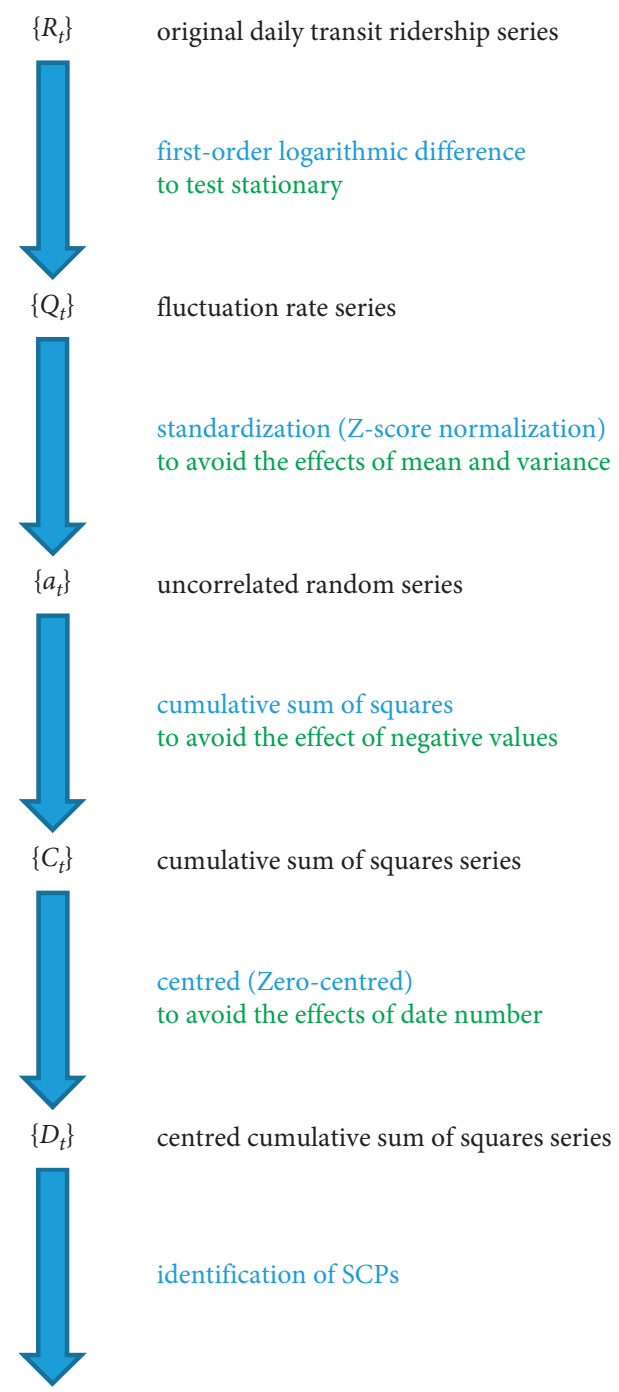

FIgURE 2: Calculation flow chart of ICSS algorithm.
4.2. Regression Discontinuity ( $R D)$ Method. Regression discontinuity (RD) analysis is a rigorous nonexperimental method that can be used to estimate program impacts in situations in which candidates are selected for treatment based on whether their value for a numeric rating exceeds a designated threshold or cut point [29].

The RD method was first introduced by Thistlethwaite and Campbell to study the impact of scholarships on students' career planning [30]. But it was not until the late 1990s that economists took it seriously. Hahn et al. provided the $\mathrm{RD}$ method as the theoretical basis of econometrics [31]. Then, economists revived the approach, formalized it, strengthened its estimation methods, and began to apply it to many different research questions. This renaissance culminated in a 2008 special issue on RD analysis in the Journal of Econometrics. At present, the applications of RD in educational economy, labour economy, health economy, political economy, and regional economy are still on the rise.

Sharp Regression Discontinuity means that at the breakpoint, the probability of the processed individual $P_{i}$ jumps from 0 to 1 when the independent variable $x_{i}$ is equal to the breakpoint $c$. Generally, we assume that the breakpoint is a constant $c$, and the classification rule is in

$$
P_{i}= \begin{cases}1, & x_{i} \geq c, \\ 0, & x_{i}<c .\end{cases}
$$

Before the experiment, a linear relationship between the dependent variable $y_{i}$ and independent variable $x_{i}$ should be supposed, as shown in

$$
y_{i}=\alpha+\beta x_{i}+\varepsilon_{i}(i=1, \ldots, n) .
$$

Since there is no systematic difference in all aspects of the individual near $x=c$, the only reason for the jump in the conditional expectation function $E\left(y_{i} \mid x\right)$ here is only the processing effect $P_{i}$. To estimate this jump, equation (7) is rewritten as

$$
y_{i}=\alpha+\beta\left(x_{i}-c\right)+\delta P_{i}+\gamma\left(x_{i}-c\right) P_{i}+\varepsilon_{i}(i=1, \ldots, n),
$$

where $\left(x_{i}-c\right)$ is the standardization of variable $x_{i}$, making $y_{i}=0$ when $x_{i}$ is equal to $c$. Introducing an interactive item $\gamma\left(x_{i}-c\right) P_{i}$ allows different slopes on both sides of the breakpoints. Then, the local average effect $\delta$ can be estimated when $x_{i}$ is equal to $c$ by using the OLS (Ordinary Least Squares) regression.

The linear regression discontinuity method was applied between two adjacent SCPs. The growth trend of this stage can be obtained from the slope. It is also possible to test whether similar equations exist between different intervals. 


\section{Results and Discussion}

5.1. Construction of Time Series for Ridership. The ridership series is a data sequence with an interval length of one day. There is no missing value during this period from Jan $1^{\text {st }}$, 2018 to Jun $30^{\text {th }}, 2019$ (see Figure 3 ). The time series of total daily ridership time series fluctuates greatly with the date due to the following reasons:

(i) Impact of the weekends (see Table 4)

(ii) Impact of the holidays (see Table 4)

(1) Xiamen is a tourist city. The metro ridership increases significantly during holidays, especially on Labour Day and National Day. In addition, Jan $1^{\text {st }}, 2018$ is the New Year's Holiday. As the new metro had just been opened, many citizens were eager to experience the new kind of transit. Therefore, ridership on Jan $1^{\text {st }}, 2018$ was much more than that on other days.

(2) Although there is more ridership on most holidays than that on weekdays and weekends, ridership during the Spring Festival is an exception. Spring Festival is the most important reunion festival in Chinese culture. The large foreign population from other cities led to a sharp decline in the number of passengers around the Spring Festival.

(3) In addition to holidays, ridership on weekdays near the holidays also has similar characteristics to that on holidays. This is because some passengers travel before or after the holidays to avoid congestion.

(iii) Impact of extreme weather. Xiamen is a coastal city, which often suffers from extreme weather, such as rainstorms and typhoons. Many passengers will choose cars and taxis to avoid delay and inconvenience.

Finally, 265 samples were selected to identify SCPs using the ICSS algorithm. Daily ridership time series can also be dynamically monitored.

5.2. Result of SCPs Identification. Stationary test results can be easily obtained from the adftest function in the Econometrics Toolbox of Matlab software. If the time series is stationary, the answer is 1 , otherwise, the answer is 0 . The initial daily transit ridership $\left\{R_{t}\right\}$ is not a stationary time series. However, the fluctuation rate series $\left\{Q_{t}\right\}$ is a stationary time series.

To better demonstrate the ICSS method, intermediate results are shown in Figure 4. The curve shapes of fluctuation rate series and uncorrelated random series are similar because uncorrelated random variables are the standardization of fluctuation rates. There are larger positive values and smaller negative values when SCPs are present (see Figure 4(b)). Values of the cumulative sum of squares are incremental and jump sharply when there are SCPs (see Figure $4(\mathrm{c})$ ). The values of the centered cumulative sum of squares are around 0 if there are no SCPs. SCPs will be identified if values of the centered cumulative sum of squares exceed the predetermined threshold (see Figure 4(d)).

With 95\% confidence, three SCPs were identified, and the time series was divided into four segments. The regression discontinuity method was utilized to explore the correlation between the total ridership ( $Y$-axis) and the date (X-axis) (see Figure 5).

The second interval, from early July to the end of August, coincides with the summer vacation dates of Chinese students and the best tourist dates in Xiamen. The slope of the third linear regression equation is much higher than that of the other three equations, which indicates that the total ridership increased rapidly at this stage due to the influence of the preferential schemes. However, due to the end of a certain preferential scheme reducing attractiveness to passengers, the slope of the fourth linear regression equation is lower than that of the third equation. The $R^{2}$ values of the first and second linear regression equations are smaller, while the $R^{2}$ values of the third and fourth linear regression equations are closer to 1 . This phenomenon indicates that the variability of ridership was larger in the early stages after the metro operation and that the ridership increased steadily after a period of operation.

\subsection{Discussion of Effects of Fare Discounts on Different Ticket} Types. The SCPs of ridership varied by ticket types were identified to explore the impact of fare discount schemes on ticket types (see Figure 6).

\subsubsection{Effects of Fare Discounts on Single Tickets and Other} Tickets. Similar to the total ridership, there are two SCPs of the ridership time series of Single Tickets. The interval between the two SCPs is from the beginning of July to the end of August, which coincides with the best tourist dates in Xiamen. Tourists were likely not to buy a smart card or download the "Xiamen Metro" APP specifically for this tour. In addition, some passengers, especially the elderly and child tourists, were not familiar with the APP and cannot obtain E-Tickets from the APP. Thus, Single Tickets are one of the most popular choices for tourists. Therefore, it is understandable that ridership for Single Tickets increases during the summer vacation.

With 95\% confidence, there is no SCP of the ridership of Other Tickets, because fewer passengers use Other Tickets, which are all specific special ticket types.

5.3.2. Effects of Fare Discounts on E-Tickets. Interestingly, the dates of the SCPs coincide precisely with the start and end dates of the "2 RMB Discount" preferential scheme. During the dates of the two SCPs, the ridership of E-Tickets exhibits a linear and rapid growth.

Another interesting phenomenon is that after the launch of the " 2 RMB Discount" preferential scheme, ridership did not increase suddenly, but gradually at a greater growth rate. This phenomenon may be due to the gradual understanding and adaptation of residents. The 


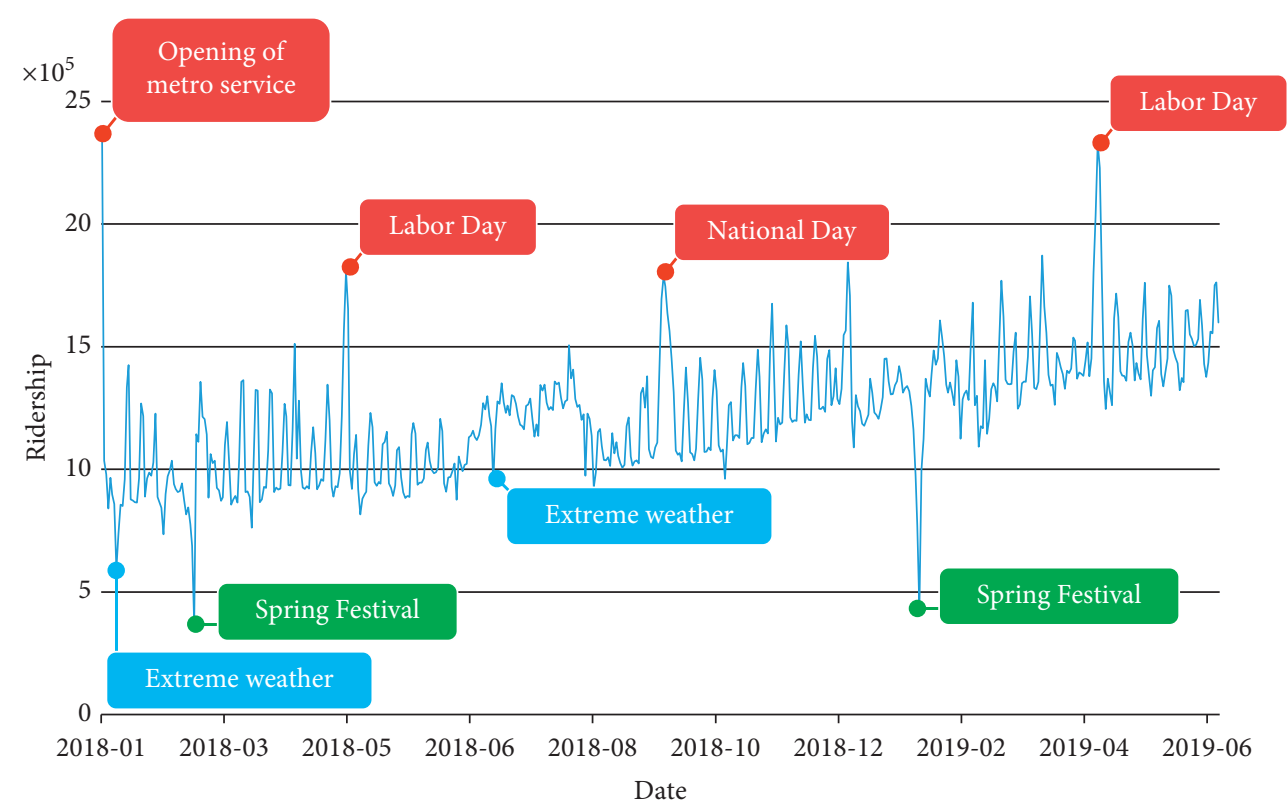

FIgURE 3: Raw data of daily total ridership time series with all dates.

allowance provider of the " 2 RMB Discount" preferential scheme was the Banking Alliance, not the Xiamen government or Xiamen Metro Group. The dissemination of preferential information also takes time, and this process is more likely to be word-of-mouth.

Unfortunately, the goal of the " 2 RMB Discount" preferential scheme was to increase the influence of the Banking Alliance and promote their paid APP (UnionPay) by taking advantage of the opening of the new metro. Citizens found that the discount was weakened after the end of the " 2 RMB Discount" preferential scheme. So, the ridership of the E-Tickets plummeted significantly. The ridership on Jan $2^{\text {nd }}, 2019$ decreased by $26.89 \%$ compared with that on Dec $27^{\text {th }}, 2018$.

5.3.3. Effects of Fare Discounts on Smart Card Tickets. With $95 \%$ confidence, there was no SCP in the ridership of Smart Card Tickets. The ridership of Smart Card Tickets still fluctuated and there were even upward and downward trends. However, this process was gradual, not abrupt. Thus, the ICSS method based on variance mutation did not identify SCPs of the ridership of Smart Card Tickets.

The "50\% Discount" preferential scheme ensured the slow growth of ridership, although this incentive scheme was not as attractive as the " 2 RMB Discount" preferential scheme. In a sense, most users of the Smart Card Tickets and E-Tickets are Xiamen residents. Therefore, there was an opposite growth trend in the ridership of the Smart Card Tickets and E-Tickets. During the period of the " 2 RMB Discount" preferential scheme, there was a downward trend in the ridership of Smart Card Tickets, while the ridership of E-Tickets increased.

However, after the end of the "2 RMB Discount" preferential scheme, there was an upward trend in the ridership of Smart Card Tickets, which exhibited a similar growth rate to that of E-Tickets. This win-win situation of Smart Card Tickets and E-Tickets may be caused by the internal driving effect of the metro.

5.4. Maintained, Induced, and Disappeared Ridership. Figure 6 clearly shows the trend from 2018/9/22 to 2019/1/2 when the share of Smart Card Tickets decreased and the share of E-Tickets increased at the same time. Unfortunately, passengers using Smart Card Tickets are marked with smart card numbers, while passengers using E-Tickets are marked with mobile phone numbers. There are no relationships between card numbers and mobile phone numbers. Therefore, there is a lack of direct evidence to accumulate the number of passengers shifting from Smart Card Tickets to E-Tickets.

We gave an example to illustrate this problem from the side. We chose passengers using Smart Card Tickets or E-Tickets that appeared in August 2018 or December 2018 or June 2019 as a whole. These three months were chosen because they were the last month of a certain stage. In these months, ridership was the most stable and travel characteristics were the most responsive. In Figure 7, grey boxes represent the proportion of passengers that appear in a certain month, while white boxes stand for the proportion of passengers that did not appear in a certain month.

Among all passengers using E-Tickets, 54.84 percent of passengers were induced from other modes of transport or Smart Card Tickets after the start of "2 RMB Discount." Subsequently, 34.98 percent of passengers were maintained while 19.86 percent of passengers disappeared after the end of "2 RMB Discount." 26.83 percent of passengers travelled in August 2018. After the incentives of " 2 RMB Discount," 54.84 percent of passengers travelled in December 2018. Although the most affordable scheme of " 2 RMB Discount" ended on $2018 / 12 / 31$, the new discount scheme of " $50 \%$ Discount" 


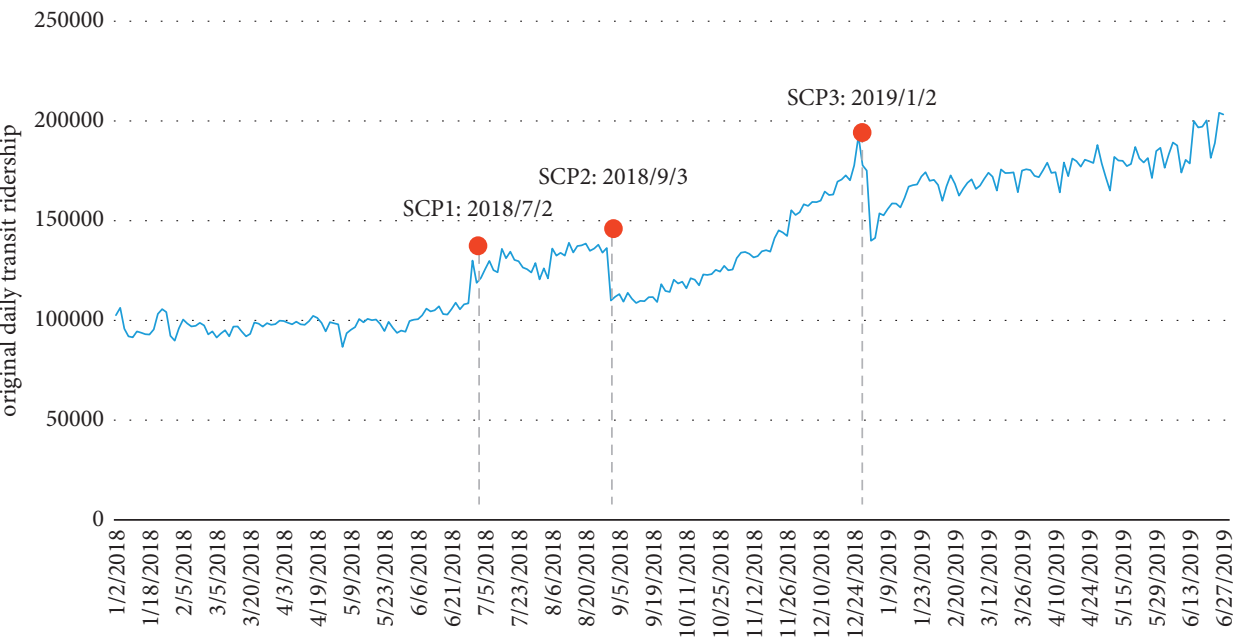

date

(a)

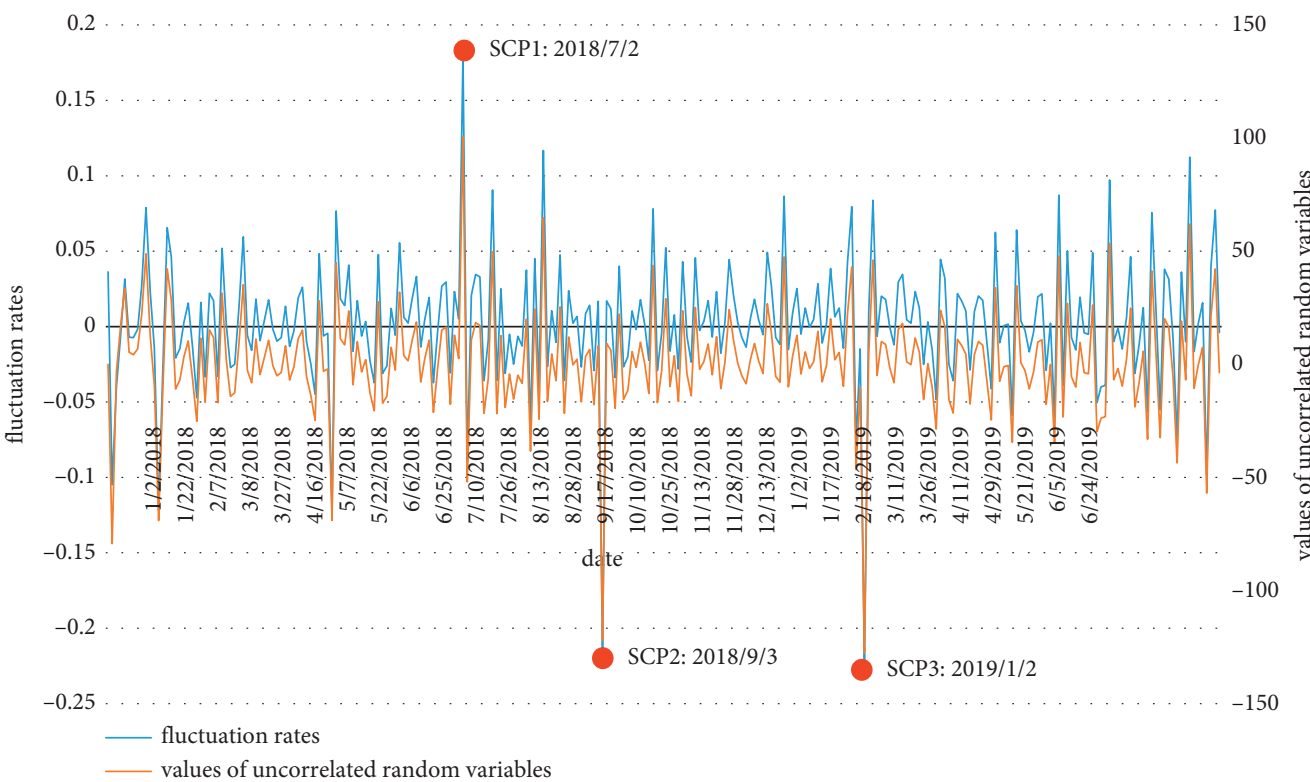

(b)

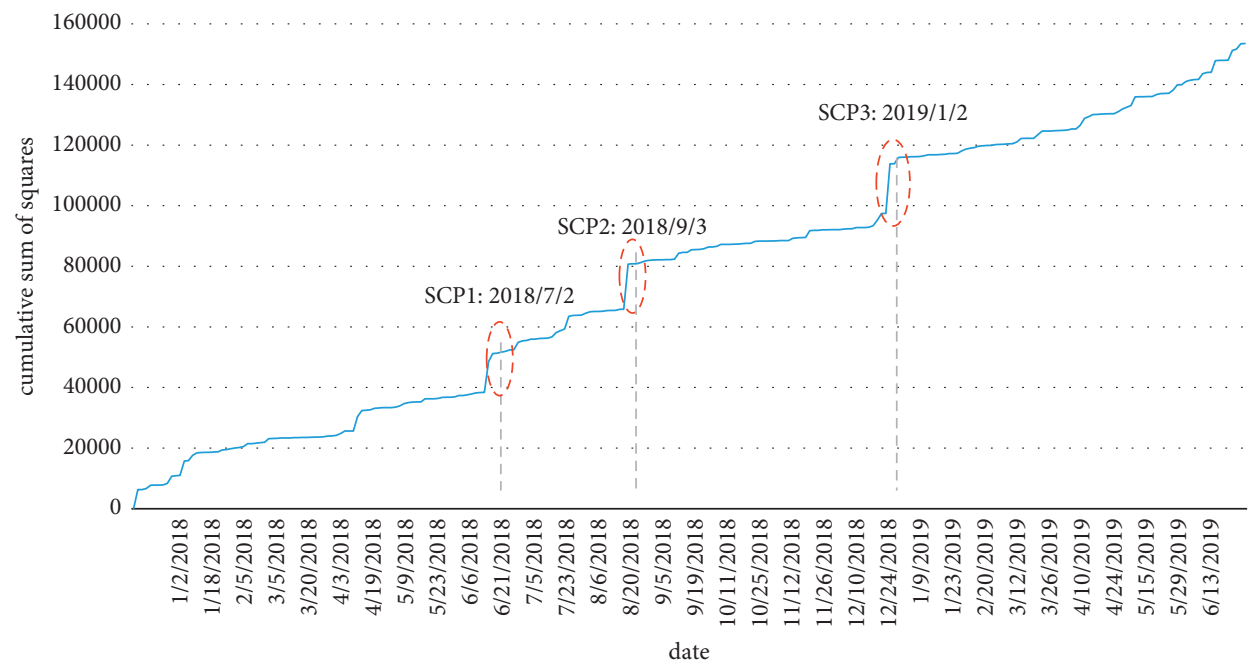

(c)

FIgUre 4: Continued. 


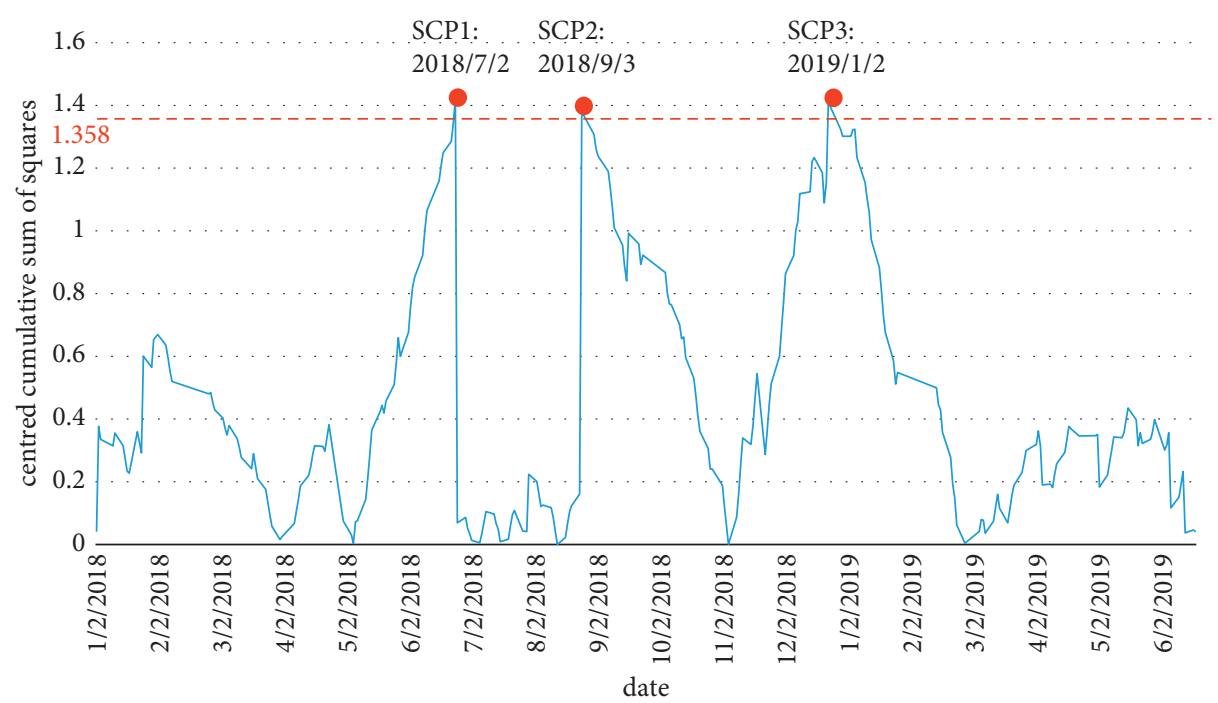

(d)

FIgURE 4: Intermediate results of ICSS method. (a) Original daily transit ridership. (b) Fluctuation rate series and uncorrelated random series. (c) Cumulative sum of squares. (d) Centered cumulative sum of squares.

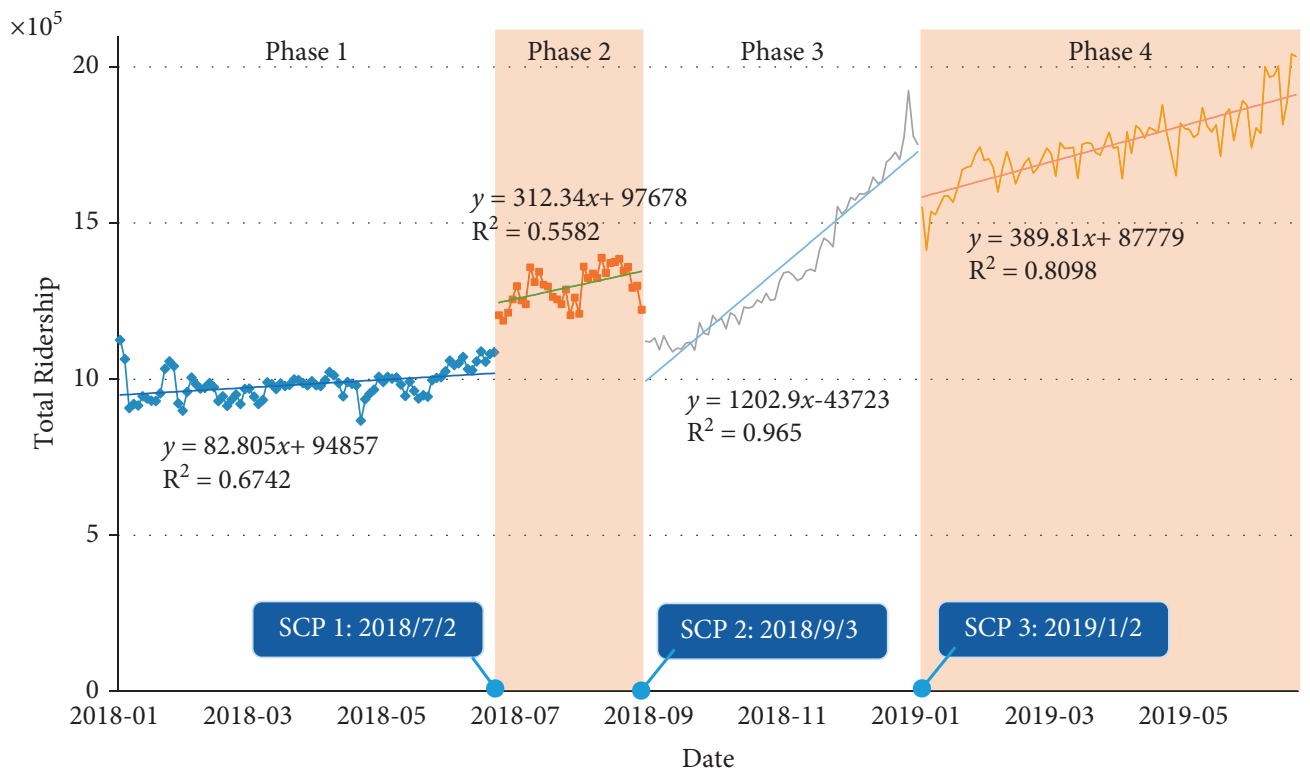

FIGURE 5: Regression discontinuity result of the total ridership time series with the chosen dates.

replaced "2 RMB Discount." 53.31 percent of passengers travelled in June 2019. There was no significant decrease compared with passengers in December 2018 (see Figure 7(b)).

Among all passengers using Smart Card Tickets, 28.49 percent of passengers disappeared after the start of the " 2 RMB Discount." Owing to the more favorable discount scheme, they may shift from Smart Card Tickets to E-Tickets (see Figure 7(a)).

5.5. Analysis of Passengers with Discount. Compared with the "10\% Discount" preferential scheme, the "2 RMB Discount" preferential scheme is more favorable; compared with the
“50\% Discount” preferential scheme, the " 2 RMB Discount" preferential scheme is more direct without an accumulated fare. Short-distance passengers can even take the metro for free, while long-distance passengers can reduce their travel costs: two preferential rides per passenger per day, which is also very attractive to commuters. As a result, once the concessionary scheme is launched, the ridership surges steadily. " $50 \%$ Discount" is a cumulative discount for highfrequency passengers. If the cumulative cost is less than 40 $\mathrm{RMB}$, passengers will not be able to enjoy the " $50 \%$ Discount." Therefore, this discount scheme is not available to all passengers, and it tends to subsidize high-frequency passengers. 


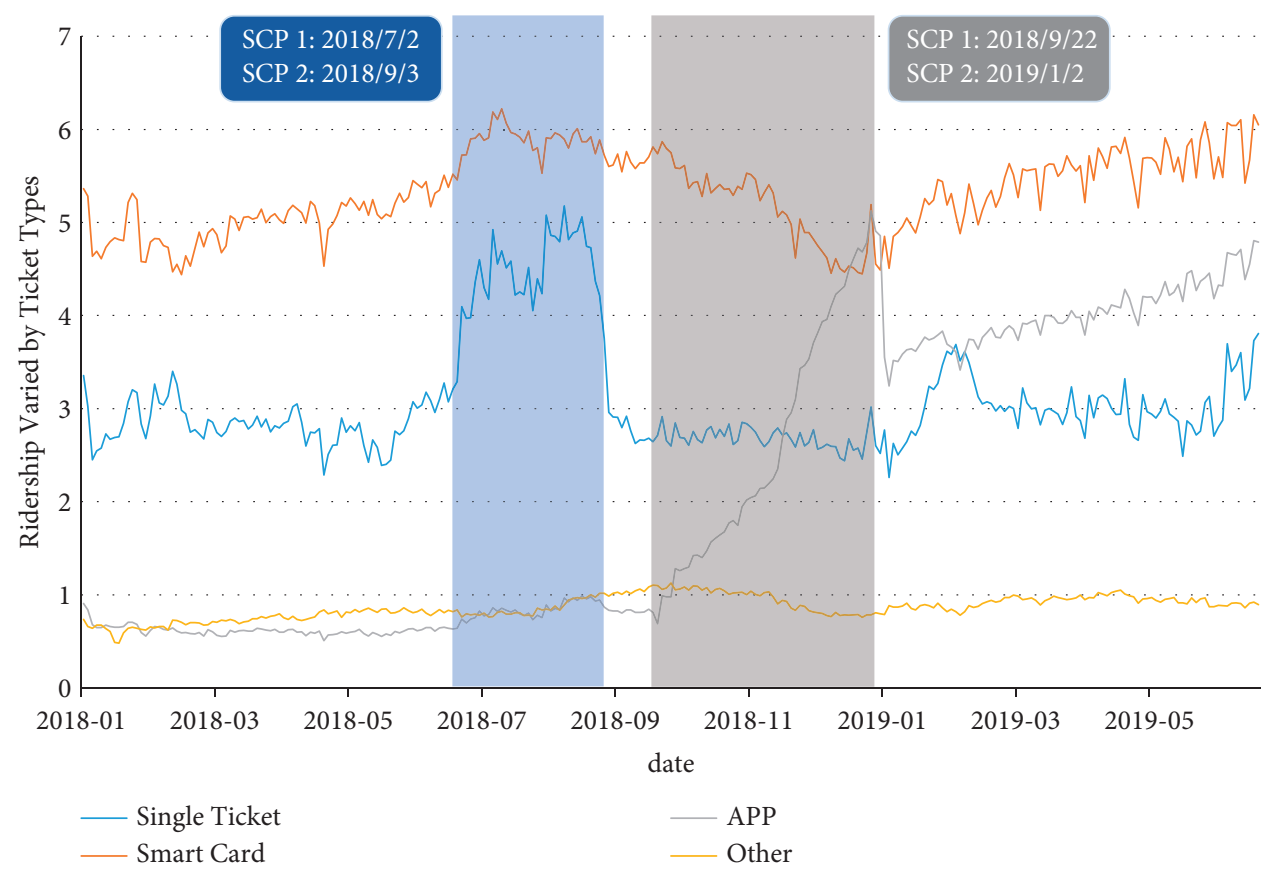

FIGURE 6: ICSS result of ridership time series varied by ticket types with the chosen dates.

5.5.1. Passengers Using the Same Ticket with Different Discounts. From 2018/12/01 to 2018/12/31, passengers using E-Tickets can enjoy both " 2 RMB Discount" and " $50 \%$ Discount." Each passenger can enjoy the "2 RMB Discount" twice per day, and only high-frequency passengers whose total cost is more than 40 RMB enjoy the " $50 \%$ Discount."

The group enjoying both " 2 RMB Discount" and " $50 \%$ Discount" accounts for 23.80 percent of the total number of passengers, with the ratio of 69.08 percent of travels all day and 79.05 percent of travels in the peak hours. While the group with "2 RMB Discount" only accounts for 76.20 percent of the total number of passengers, with the ratio of 30.92 percent of travels all day and 20.95 percent of travels in the peak hours. Average trips per month of the group with both " 2 RMB Discount" and " $50 \%$ Discount" are 31.34 , which is much higher than that of the group with " $2 \mathrm{RMB}$ Discount" only (4.38). Similarly, the average travel days per month of the group with both " 2 RMB Discount" and " $50 \%$ Discount" are 17.52, which is much higher than that of the group with "2 RMB Discount" (only 3.13). Average trips per day of the group with both " 2 RMB Discount" and " $50 \%$ Discount" are 1.78, which is higher than that of the group with "2 RMB Discount" only (1.39). There are no significant differences between the two groups when talking about stations per travel. Assuming that these two discount schemes do not exist, the group with both " 2 RMB Discount" and " $50 \%$ Discount" will spend $87.88 \mathrm{RMB} / \mathrm{month}$. But now they just spend $24.53 \mathrm{RMB} /$ month. Groups with "2 RMB Discount" only spend $7.48 \mathrm{RMB} /$ month now and 16.82 $\mathrm{RMB} /$ month without these two discount schemes. Thanks to these two discount schemes, the cost per trip of the group with both " 2 RMB Discount" and " $50 \%$ Discount" (0.99) is much lower than that of the group with " 2 RMB Discount" only (1.92). In general, there are more travels of the group with both " 2 RMB Discount" and " $50 \%$ Discount" than groups with "2 RMB Discount" only, because " $50 \%$ Discount" is more beneficial to high-frequency passengers, possibly commuters (see Table 5).

5.5.2. Passengers Using Different Tickets with the Same Discount. Passengers who use Smart Card Tickets and E-Ticket both enjoy a "50\% Discount" from 2019/01/01 to $2019 / 06 / 30$. We defined a group with discounts as the passengers who enjoy the " $50 \%$ Discount."

The group with a discount while using E-Tickets account for 19.79 percent of the total number of passengers with the ratio of 65.41 percent of travels all day and 55.07 percent of travels in the peak hours. While the group with a discount using Smart Card Tickets account for 7.57 percent of the total number of passengers with the ratio of 32.43 percent of travels all day and 45.97 percent of travels in the peak hours. Average trips per month for E-Ticket users are 31.28, much higher than that for Smart Card Tickets users (15.99). Similarly, the average travel days per month for E-Ticket users are 17.14, much higher than that for Smart Card Tickets users (9.83). Average trips per month and average travel days per month for the group with a discount are in sharp contrast to the group without a discount. Average trips per day of E-Tickets group with discount are 1.79, just a little higher than that of the other three groups. There are no significant differences between the four groups when talking about stations per travel. Assuming that the "50\% Discount" does not exist, E-Ticket users with a discount will spend 119.41 RMB/month, but now they just spend 80.30 RMB/ month on the metro fare. Smart Card Tickets group with discount spend $40.26 \mathrm{RMB} / \mathrm{month}$, and other two groups spend lower fares. Due to the " $50 \%$ Discount," the cost per 


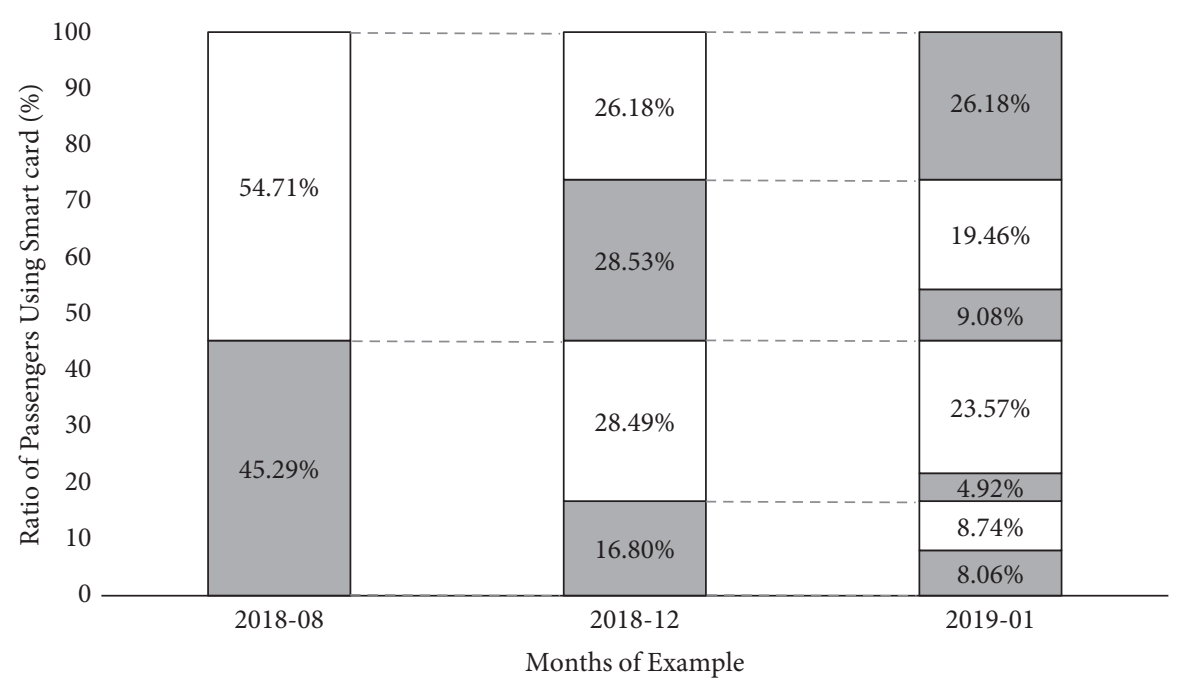

(a)

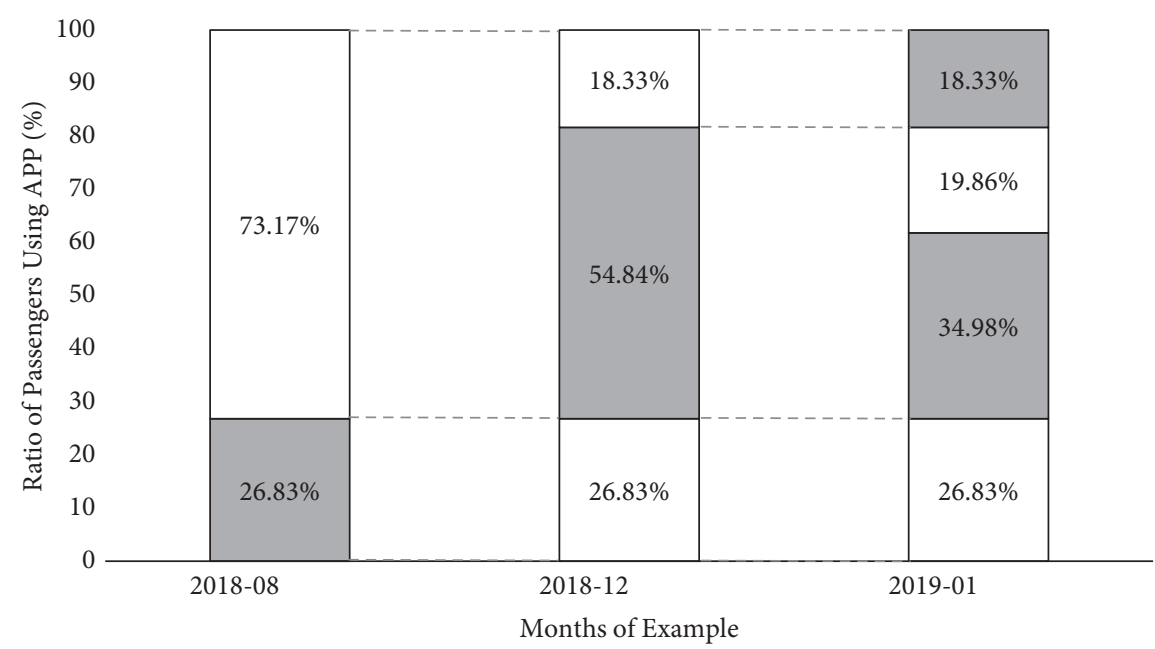

(b)

Figure 7: Maintained, induced, and disappeared ridership (grey: appear; white: disappear). (a) Smart Card Tickets. (b) E-Tickets.

trip of the group with a discount is lower than that of the group without a discount. Overall, there are more travels of the group with the discount than the group without a discount. Travel characteristics of E-Ticket users are more than that of Smart Card Tickets users, possibly because commuters are more likely to use E-Tickets (see Table 6).

Comparing Tables 5 and 6, travel characteristics, such as average trips per month, average travel days per month, average trips per day, etc., are similar to E-Ticket passengers both with discounts in Tables 5 and 6. Thanks to the " 2 RMB Discount," travel costs have been greatly reduced. Passengers spent only $0.99 \mathrm{RMB}$ per trip to take the metro if they enjoy both " 2 RMB Discount" and " $50 \%$ Discount." Low fees have greatly stimulated the growth of ridership.

5.6. Policy Recommendations. There is no doubt that fare discounts have a significant impact on ridership. E-Tickets are popular with users, especially high-frequency commuters because E-Tickets are more convenient to carry than
Reality Cards, which should attract the attention of the governments and metro operators. Similar to the law of two to eight, fewer passengers produce more travel. Regardless of accumulated standards, the reduced cost of each trip will attract low-frequency passengers. Therefore, after the opening of the first metro line, money reduced per trip is the perfect discount scheme to attract bus passengers and car drivers to transfer to the metro system. When passengers spent less using one ticket type, they will give up using the previous ticket type to obtain the discount. When the discount schemes end, passengers will give up taking the metro or choose other ticket types. However, the number of passengers that increased due to the discount schemes is much more than that before the start of preferential policies. In the peak tourist season, Single Tickets are more popular with tourists.

This is an excellent cooperation mode of "tripartite winwin." First of all, these preferential measures not only help to reduce the operating pressure of the government and the metro operators but also help to promote the optimization of 
TABLE 5: Travel characteristics of passengers using the same tickets with a different discount (2018/12/01-2018/12/31).

\begin{tabular}{lcc}
\hline Index & $\begin{array}{c}\text { The group with both “2 RMB discount" and “50\% } \\
\text { discount” }\end{array}$ & $\begin{array}{c}\text { The group with "2 RMB discount" } \\
\text { only }\end{array}$ \\
\hline Ratio of passengers & $23.80 \%$ & $76.20 \%$ \\
Ratio of travels & $69.08 \%$ & $30.92 \%$ \\
Ratio of travels in the peak-hours & $79.05 \%$ & $20.95 \%$ \\
Average trips per month (average travel days per & $31.34(17.52)$ & $4.38(3.13)$ \\
month) & 1.78 & 1.39 \\
Average trips per day & 7.93 & 7.73 \\
Stations per travel & & $7.48(16.82)$ \\
Cost per month (original cost without $50 \%$ & $24.53(87.88)$ & \\
discount per & & 0.99 \\
month), unit: RMB/month & & 1.92 \\
Cost per trip, unit: RMB/trip & & \\
\hline
\end{tabular}

TABLE 6: Travel characteristics of passengers using different tickets with the same discount (2019/01/01-2019/06/30).

\begin{tabular}{|c|c|c|c|c|}
\hline \multirow[b]{2}{*}{ Index } & \multicolumn{2}{|c|}{ Smart card tickets } & \multicolumn{2}{|c|}{ E-Tickets } \\
\hline & Group with discount & Group without discount & $\begin{array}{l}\text { Group with } \\
\text { discount }\end{array}$ & $\begin{array}{c}\text { Group without } \\
\text { discount }\end{array}$ \\
\hline Ratio of passengers & $7.57 \%$ & $92.43 \%$ & $19.79 \%$ & $80.21 \%$ \\
\hline Ratio of travels & $32.43 \%$ & $67.57 \%$ & $65.41 \%$ & $34.59 \%$ \\
\hline Ratio of travels in the peak-hours & $45.97 \%$ & $30.14 \%$ & $55.07 \%$ & $32.12 \%$ \\
\hline $\begin{array}{l}\text { Average trips per month (average travel days per } \\
\text { month) }\end{array}$ & $15.99(9.83)$ & $2.71(2.03)$ & $31.28(17.14)$ & $4.02(2.92)$ \\
\hline Average trips per day & 1.57 & 1.33 & 1.79 & 1.37 \\
\hline Stations per travel & 7.25 & 7.54 & 7.54 & 7.89 \\
\hline $\begin{array}{l}\text { Cost per month (original cost without } 50 \% \text { discount per } \\
\text { month), unit: } \mathrm{RMB} / \text { month }\end{array}$ & $40.26(59.66)$ & $9.08(10.10)$ & $80.30(119.41)$ & $13.83(15.37)$ \\
\hline Cost per trip, unit: $\mathrm{RMB} /$ trip & 2.51 & 3.34 & 2.57 & 3.44 \\
\hline
\end{tabular}

the ridership structure. Secondly, metro passengers can enjoy real benefits. Third, the market share and influence of these financial companies have also increased. Therefore, paying attention to the preferential measures launched by financial companies will help to provide a reference for the government and metro operators to seek follow-up cooperation.

Therefore, the policy recommendations are mainly about the following:

(1) Raising the focus on E-Tickets

(2) Selecting more friendly preferential measures for low-frequency passengers to transfer passengers from buses and cars

(3) Paying attention to high-frequency passengers because they contribute more travel

(4) Seeking common subsidies from the financial industry to achieve win-win results

\section{Conclusions}

To test the impact of preferential schemes on ridership varied by different card types, the iterated cumulative sums of squares (ICSS) algorithm and regression discontinuity (RD) method were introduced. 18-month transaction data after the opening of the new metro was obtained, and ultimately 265-weekday samples were selected, excluding special circumstances. Long-term data provide an excellent opportunity for the dynamic observation of the effects of preferential schemes. The dates of structural change points (SCPs) were well matched with the start and end dates of preferential schemes.

The following conclusions can be drawn:

(1) There are significant differences in ridership on weekdays, weekends, and holidays. Apart from extreme weather, preferential schemes are also important factors affecting metro ridership.

(2) There are three preferential schemes in Xiamen after the opening of the new metro line: discount per trip, money reduced per trip, and discount after reaching the accumulated fare. There are different effects on ridership varied by ticket type for different preferential schemes. The most popular preferential scheme (money reduced per trip) is the most preferential and direct scheme without other conditions, such as accumulated fare.

(3) Each preferential scheme has its own benefited groups. Low-frequency passengers can benefit from the scheme of money reduced per trip. Governments and transit operators can formulate appropriate preferential schemes to guide car/taxi passengers to shift to public transport. While high-frequency passengers can obtain more benefits from the scheme of discount after reaching accumulated fare, 
E-Tickets are more popular with high-frequency passengers, especially commuters. Governments and transit operators also need to pay attention to these passengers, because they contribute more travel.

(4) Interestingly, the residents' understanding and adaptation to the preferential schemes are gradual. Nevertheless, if the favorable preferential scheme is canceled, the number of passengers will drop sharply. Passengers will shift from a ticket type to another owing to the more favorable discount scheme. On the whole, the number of passengers increased due to the discount schemes is much higher than that before the preferential policy began.

However, we would prefer to analyze the transfer behavior from other modes of transport or between different ticket types with more data. The ICSS algorithm and RD method can also be used to evaluate the effectiveness of other transportation policies in the future.

\section{Data Availability}

The data used to support the findings of this study are available from the corresponding author upon request.

\section{Conflicts of Interest}

The authors declare that there are no conflicts of interest regarding the publication of this paper.

\section{Acknowledgments}

This work was supported by the National Natural Science Foundation of China (Grant no. 71734004), the Technology Project of Fujian Province, China (Grant no. 2017Y062), and the Fundamental Research Funds for the Central Universities (Grant no. 300102210126).

\section{References}

[1] China Association of Metros, "Urban rail transit statistics and analysis report (2015-2020)". https://www.camet.org.cn/.

[2] Y. Wang, L. Li, Z. Wang, T. Lv, and L. Wang, "Mode shift behavior impacts from the introduction of metro service: case study of Xi'an, China," Journal of Urban Planning and Development, vol. 139, no. 3, pp. 216-225, 2013.

[3] J. C. Golias, "Analysis of traffic corridor impacts from the introduction of the new Athens Metro system," Journal of Transport Geography, vol. 10, no. 2, pp. 91-97, 2002.

[4] N. Sharaby and Y. Shiftan, "The impact of fare integration on travel behavior and transit ridership," Transport Policy, vol. 21, pp. 63-70, 2012.

[5] Y. Yang, "Review on urban public transport subsidy," Productivity Research, vol. 8, pp. 206-209, 2011.

[6] Q. Yu, H. Zhang, W. Li et al., "Mobile phone data in urban bicycle-sharing: market-oriented sub-area division and spatial analysis on emission reduction potentials," Journal of Cleaner Production, vol. 254, Article ID 119974, 2020.

[7] Q. Yu, H. Zhang, W. Li, X. Song, D. Yang, and R. Shibasaki, "Mobile phone GPS data in urban customized bus: dynamic line design and emission reduction potentials analysis,"
Journal of Cleaner Production, vol. 272, Article ID 122471, 2020.

[8] C. Inclan and G. C. Tiao, "Use of cumulative sums of squares for retrospective detection of changes of varience," Journal of the American Statistical Association, vol. 89, no. 427, pp. 913-923, 1994.

[9] W. Vickrey, "Some implications of marginal cost pricing for public utilities," The American Economic Review, vol. 45, no. 2, pp. 605-620, 1955.

[10] H. Mohring, "Optimization and scale economies in urban bus transportation," The American Economic Review, vol. 62, no. 4, pp. 591-604, 1972.

[11] K. A. Small, "The scheduling of consumer activities: work trips," The American Economic Review, vol. 72, no. 3, pp. 467-479, 1982.

[12] C.-F. Yeh and M.-T. Lee, "Effects of taichung bus policy on ridership according to structural change analysis," Transportation, vol. 46, no. 1, pp. 1-16, 2019.

[13] Victoria Transport Policy Institute, Transit Price Elasticities and Cross Elasticities, Victoria Transport Policy Institute, Victoria, Canada, 2020.

[14] P. Goodwin, "Review of new demand elasticities with special reference to short and long run effects of price changes," Journal of Transport Economics, vol. 26, no. 2, pp. 155-171, 1992.

[15] D. Gillen, Peak Pricing Strategies in Transportation, Utilities, and Telecommunications: Lessons for Road Pricing, Transportation Research Board, Washingtong DC, USA, 1994.

[16] R. Cervero, Land-use Mixing and Suburban Mobility, Transportation, Berkeley, CA, USA, 1989.

[17] R. Borndörfer, M. Karbstein, and M. E. Pfetsch, "Models for fare planning in public transport," Discrete Applied Mathematics, vol. 160, no. 18, pp. 2591-2605, 2012.

[18] X. Guo and H. Sun, "Analysis of time of day fare discounts on urban mass transit travel behaviour, crowding, and waiting time," Mathematical Problems in Engineering, vol. 2014, Article ID 686705, 6 pages, 2014.

[19] S. Farber, K. Bartholomew, X. Li, A. Páez, and K. M. Nurul Habib, "Assessing social equity in distance based transit fares using a model of travel behaviour," Transportation Research Part A: Policy and Practice, vol. 67, pp. 291-303, 2014.

[20] C. Miller and I. Savage, "Does the demand response to transit fare increases vary by Income?" Transport Policy, vol. 55, pp. 79-86, 2017.

[21] K. Gkritza, M. G. Karlaftis, and F. L. Mannering, "Estimating multimodal transit ridership with a varying fare structure," Transportation Research Part A: Policy and Practice, vol. 45, no. 2, pp. 148-160, 2011.

[22] Y. Liu, S. Wang, and B. Xie, "Evaluating the effects of public transport fare policy change together with built and non-built environment features on ridership: the case in South East Queensland, Australia,” Transport Policy, vol. 76, pp. 78-89, 2019.

[23] D. Verbich and A. El-Geneidy, "Public transit fare structure and social vulnerability in Montreal, Canada," Transportation Research Part A: Policy and Practice, vol. 96, pp. 43-53, 2017.

[24] B.-h. Nahmias-Biran, N. Sharaby, and Y. Shiftan, "Equity aspects in transportation projects: case study of transit fare change in Haifa," International Journal of Sustainable Transportation, vol. 8, no. 1, pp. 69-83, 2013.

[25] A. E. Brown, "Fair fares? How flat and variable fares affect transit equity in Los Angeles," Case Studies on Transport Policy, vol. 6, no. 4, pp. 765-773, 2018. 
[26] C. Nuworsoo, A. Golub, and E. Deakin, "Analyzing equity impacts of transit fare changes: case study of alameda-contra costa transit, California," Evaluation and Program Planning, vol. 32, no. 4, pp. 360-368, 2009.

[27] Z.-j. Wang, X.-h. Li, and F. Chen, "Impact evaluation of a mass transit fare change on demand and revenue utilizing smart card data," Transportation Research Part A: Policy and Practice, vol. 77, pp. 213-224, 2015.

[28] Z.-j. Wang, F. Chen, B. Wang, and J.-1. Huang, "Passengers' response to transit fare change: an ex post appraisal using smart card data," Transportation, vol. 45, no. 5, pp. 1559-1578, 2017.

[29] J. Robin and Z. Pei, A Practical Guide to Regression Discontinuity, MDRC, New York, NY, USA, 2012.

[30] D. L. Thistlethwaite and D. T. Campbell, "Regression-discontinuity analysis: an alternative to the ex post facto experiment," Journal of Educational Psychology, vol. 51, no. 6, pp. 309-317, 1960.

[31] J. Hahn, P. Todd, and W. Klaauw, "Identification and estimation of treatment effects with a regression-discontinuity design," Econometrica, vol. 69, no. 1, pp. 201-209, 2001. 